\title{
REDUÇÃO NO CONSUMO ESPECÍFICO (KW/T) DE ENERGIA ELÉTRICA NO MOINHO DE BAUXITA NA REFINARIA DA ALUMINA_VM-CBA*
}

\author{
Manoel Inácio dos Reis Neto ${ }^{1}$ \\ Peter Gabriel Rosa ${ }^{2}$ \\ Anderson Rodrigo Klassen Duck ${ }^{3}$
}

\section{Resumo}

Redução no consumo específico (KW/t) de energia elétrica em um dos moinhos de bauxita na refinaria da Alumina na CBA (Companhia Brasileira de Alumínio do grupo Votorantim Metais) através do uso da Metodologia Six Sigma e ações de substituição do óleo mineral por óleo sintético de alta performance, implantação do sistema de blindagem e de resfriamento no redutor deste moinho, onde foi alcançado um resultado de $5,45 \%$ de redução neste consumo específico e de $25 \%$ na temperatura de trabalho deste redutor, superando as expectativas inicias previstas.

Palavras-chave: Consumo específico alumina; Óleo sintético, Eficiência energética.

\section{ENERGY CONSUMPTION REDUCTION (KW/T) AT MILL AT BAUXITE REFINERY_VM-CBA}

\section{Abstract}

The energy consumption reduction $(\mathrm{kW} / \mathrm{t}$ ) in one of the mills at the Refinery of Bauxite at CBA (Brazilian Aluminum Company of the Metals Votorantim Group) was done through the use of Six Sigma Methodology and actions like replacement of mineral oil for synthetic oil high performance, establishment of a shield system and gear box cooling system of the mill. The achieved result was close to $5.45 \%$ in specific consumption reduction and the working temperature reduction was close to $25 \%$, exceeding the previous expectations.

Keywords: Alumina specific consumption; Synthetic oil; Energy efficiency.

1 Engenheiro Eletricista, MBA em Administração e Estratégia de Negócios, Consultor de Engenharia na área de Gestão de Energia, Gerência Geral das Salas Fornos, Companhia Brasileira de Alumínio (CBA), Alumínio, São Paulo, Brasil.

2 Engenheiro Mecânico, Engenheiro de Manutenção, Alumina, Companhia Brasileira de Alumínio, Alumínio (CBA), São Paulo, Brasil.

3 Engenheiro Químico, Engenheiro de Processos, Alumina, Companhia Brasileira de Alumínio (CBA), Alumínio, São Paulo, Brasil. 


\section{INTRODUÇÃO}

O presente documento objetiva apresentar a metodologia para determinação dos benefícios energéticos com a implantação das medidas de conservação de energia em sistemas de força motriz instalados na Unidade da CBA, em Alumínio/SP.

$\mathrm{O}$ trabalho consistiu numa primeira medição do consumo específico $(\mathrm{kWh} / \mathrm{t})$ de energia elétrica no moinho de bauxita na refinaria da Alumina, cujo redutor deste moinho era lubrificado com óleo mineral, por um período de 50 dias. Após este prazo, realizou-se a troca de todo este óleo contido no redutor, substituindo por um óleo sintético de alta performance.

Aguardado em torno de 15 dias para maturação do óleo e efetuado novas medições, observando-se as mesmas características de funcionamento.

A escolha de um lubrificante de alto rendimento teve como objetivo principal aumentar a capacidade sustentadora de cargas e a eficiência de uma engrenagem devido ao menor coeficiente de atrito, melhorando também a eficiência mecânica, o que possibilitou um menor consumo de energia elétrica.

A implantação do sistema de blindagem e de resfriamento ocorreu em virtude de problemas operacionais identificados pela área de Engenharia da Refinaria citados abaixo:

- Contaminação do óleo, por falta de blindagem no redutor;

- Troca do óleo com periodicidade semestral;

- Baixa capacidade sustentadora de cargas e deficiência nas engrenagens devido maior coeficiente de atrito entre elas;

- Maior consumo de energia elétrica, devido perda térmica;

- Desligamento do Moinho por alta temperatura do óleo mineral.

Em virtude das oportunidades citadas, foram definidas três ações: substituição do óleo mineral por um óleo sintético de alta performance, implantação de um sistema de blindagem e de resfriamento, com o objetivo de atingir os seguintes resultados:

- Redução em até 5\% no Consumo Específico (kWh/t) de bauxita do Moinho da Alumina

- Diminuição da temperatura de trabalho do redutor do moinho em até $20^{\circ} \mathrm{C}$.

\section{MATERIAIS E MÉTODOS}

\subsection{Métodos}

Para um bom andamento do projeto foi utilizado a Metodologia Six Sigma (68) do qual norteia os trabalhos de PMO (Project Management Office) da CBA.

O DMAIC (Definir, Medir, Analisar, Implementar e Controlar) foi aplicado em todas as suas etapas onde os ganhos tangíveis e intangíveis serão apresentados no item 3.

Toda a análise estatística como teste de normalidade, capabilidade inicial e final e teste de hipótese foi realizada através do Minitab (programa de computador proprietário voltado para fins estatísticos) [1].

Realizado análise dos dados medidos, através do PIMS local, entre o período de 01/05/13 a 18/06/13, onde o P-Value > 0,5, aponta um valor maior que 0,5, comprovando que os valores adquiridos são normais. 

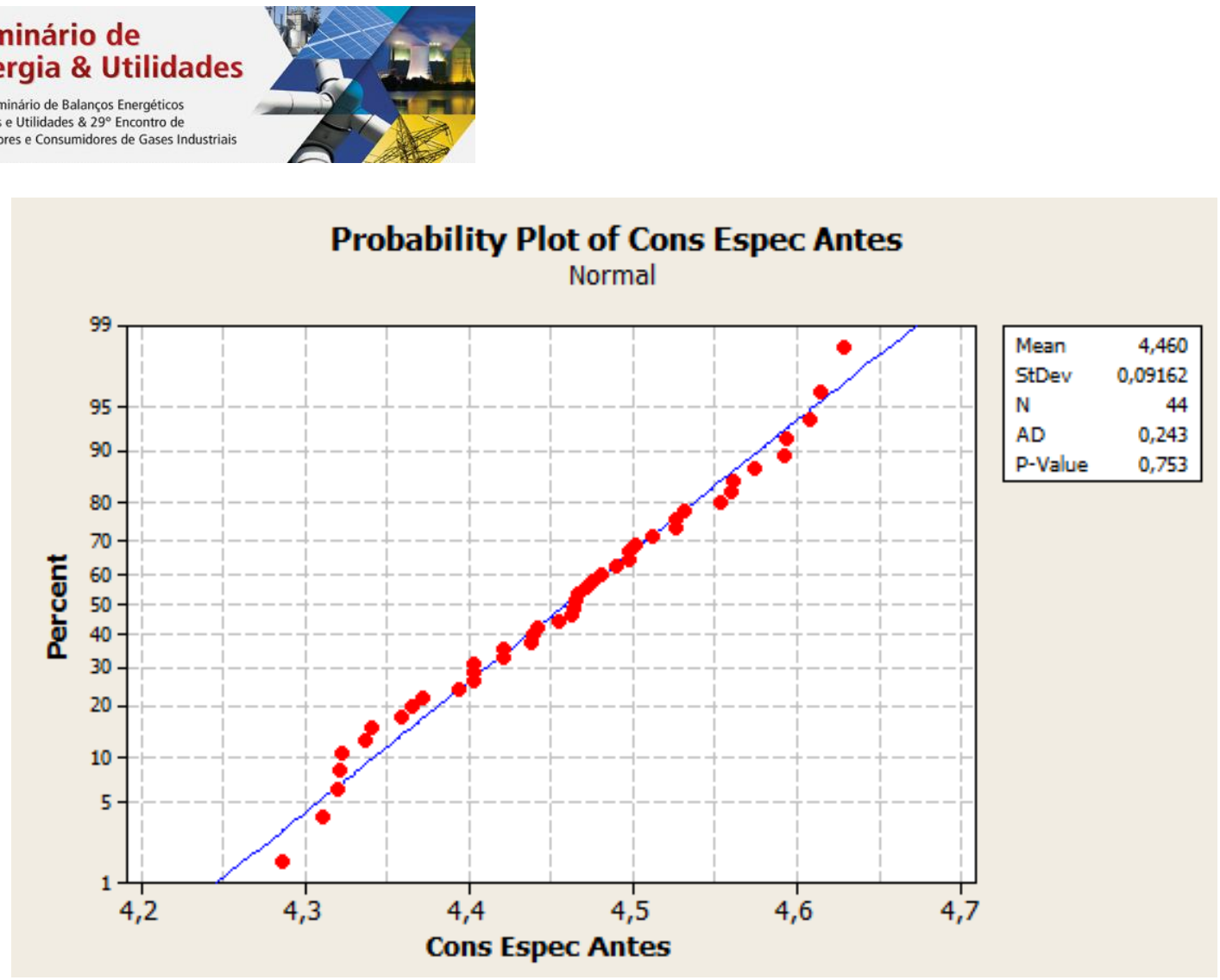

Figura 1. Resultado do Teste de Normalidade (Fase - Medir)

Em seguida foi verificado a variabilidade do processo, através do Teste de Capabilidade onde foi evidenciado um valor inicial de 0,20 o que indica que aproximadamente $41 \%$ da amostragem estava fora dos limites de especificação o que comprova problemas de instabilidade no processo.

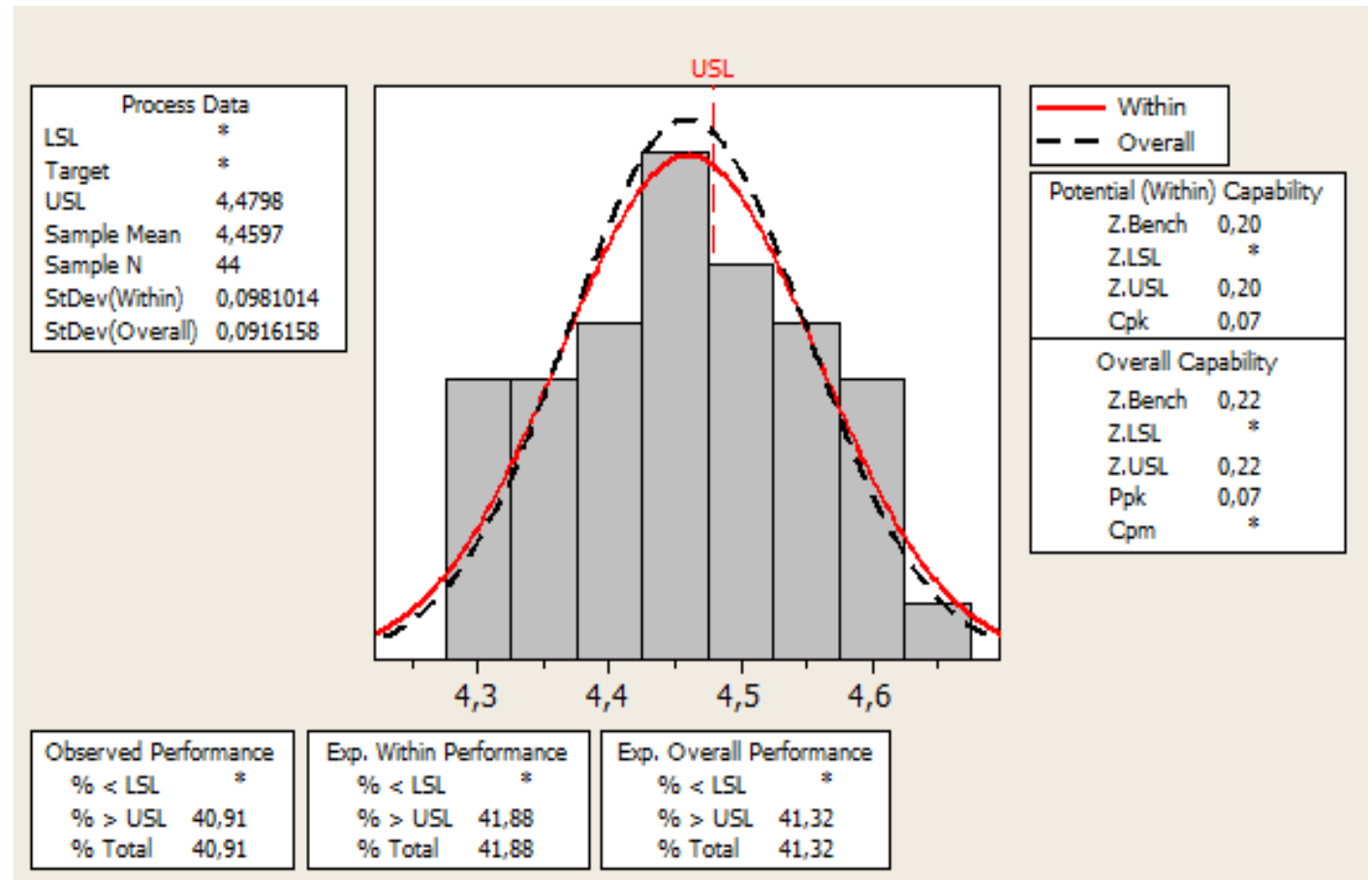

Figura 2. Resultado do Teste de Capabilidade Inicial (Fase - Medir)

$\mathrm{Na}$ fase implementar, após as ações tomadas o resultado do Teste de Capabilidade foi de 1,86 o que demonstra a eficácia destas, pois apenas $4,76 \%$ da amostragem estavam fora dos limites especificados. 

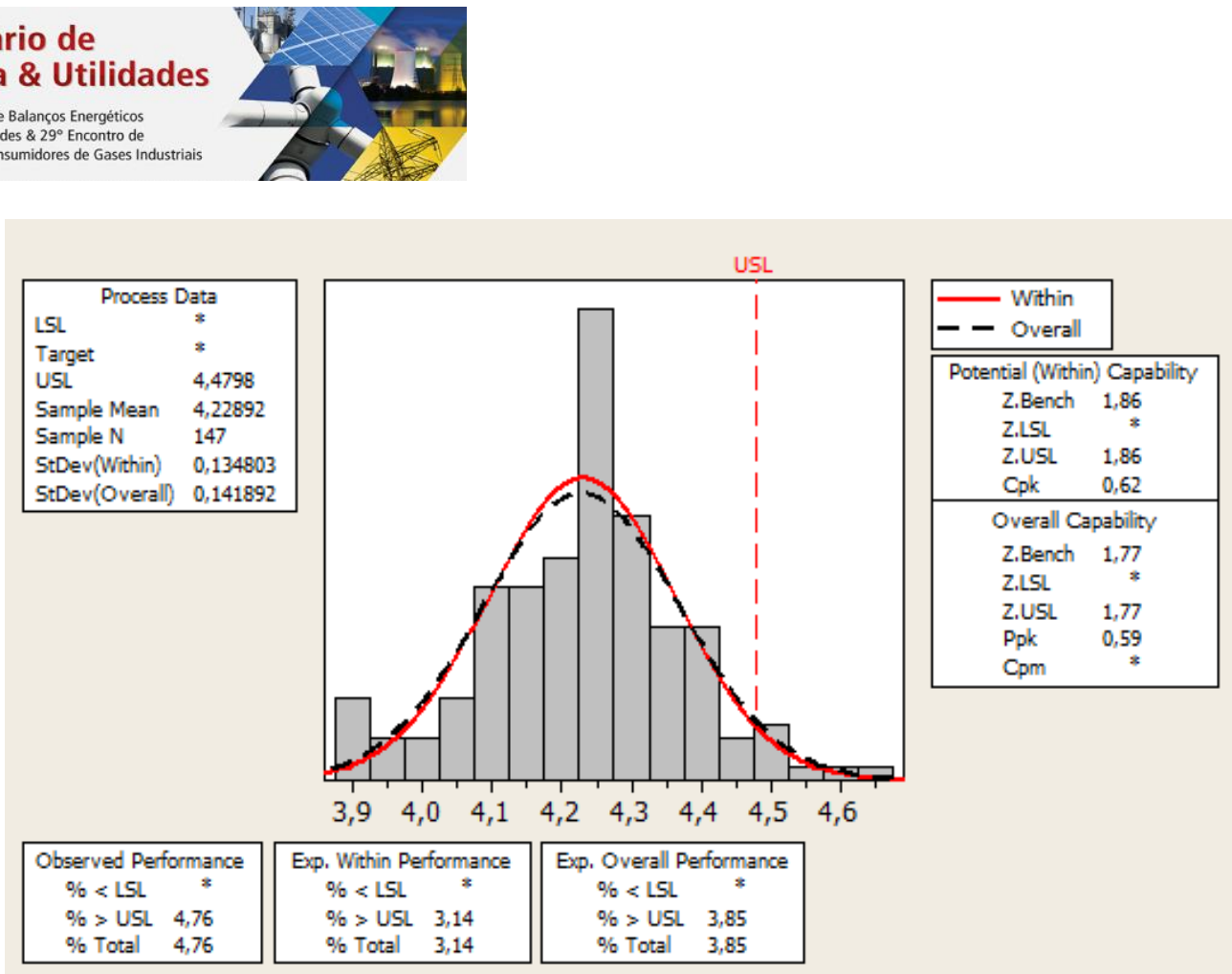

Figura 3. Resultado do Teste de Capabilidade Final (Fase - Implementar)

\subsection{Materiais}

O Redutor de velocidade é um equipamento mecânico composto por um conjunto de eixos e engrenagens que tem como função principal a redução da rotação de um motor.

O equipamento testado na CBA possui as características técnicas principais que são:

- Volume: $118 \mathrm{~L}$

- Temp Deslig: 95드

- Potência: $2000 \mathrm{hp}$ que é aproximadamente 1,49 MW.

- Viscosidade: ISO 220

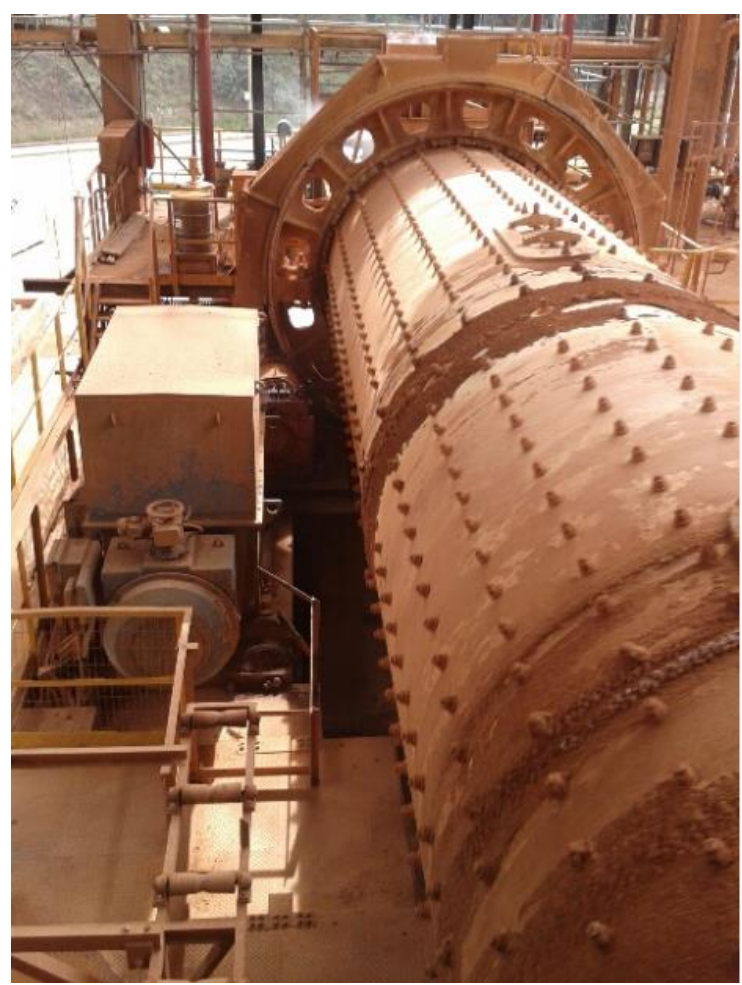

Figura 4. Moinho de Bauxita

* Contribuição técnica ao $35^{\circ}$ Seminário de Balanços Energéticos Globais e Utilidades e $29^{\circ}$ Encontro de Produtores e Consumidores de Gases Industriais, 13 a 15 de agosto de 2014, São Paulo, SP, Brasil. 

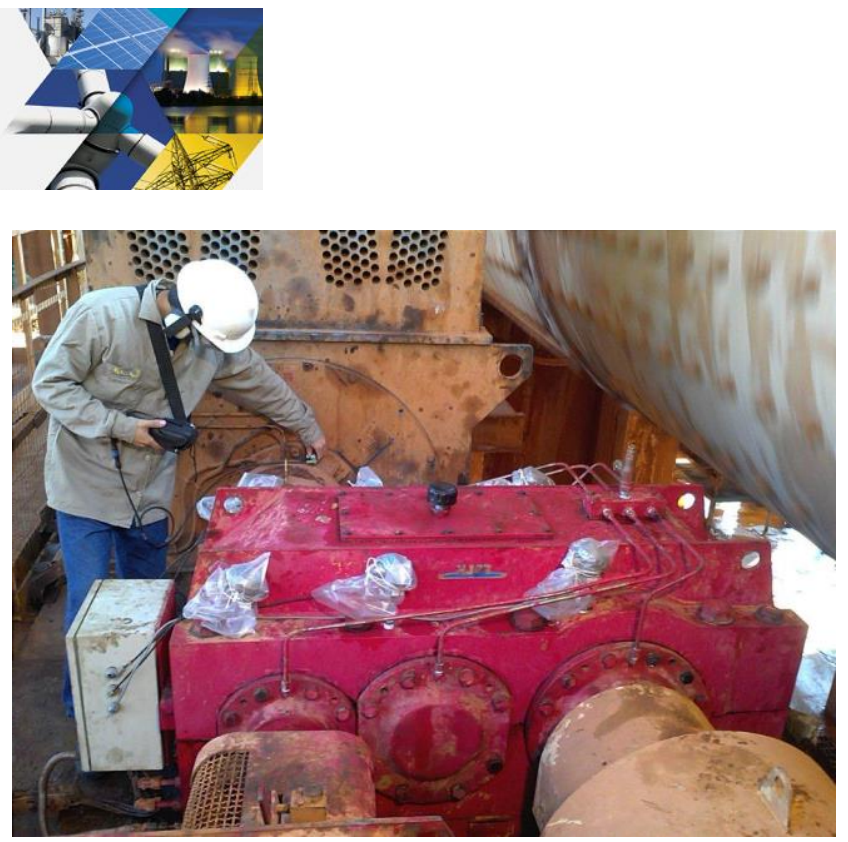

Figura 5. Redutor do Moinho

Para a implementação do projeto foram utilizados:

- Óleo sintético alta performance Mobil SHC $630 \mathrm{com}$ viscosidade ISO 220, ponto de fulgor $235^{\circ} \mathrm{C}$ e densidade específica $15^{\circ} \mathrm{C} / 15^{\circ} \mathrm{C}$ de 0,87 .

No dia 19/06/13 foi realizada a parada do moinho onde foi esgotado completamente 0 óleo mineral do redutor e inserido o óleo sintético e religado o mesmo.

Mesmo com o período de maturação do óleo (aproximadamente 15 dias) já identificouse uma redução no consumo específico de 4,24\%, conforme tabela abaixo:

Tabela 1. Ganhos efetivos óleo sintético em Junho

\begin{tabular}{|l|c|c|}
\hline \multicolumn{3}{|c|}{ MEDIÇÃO } \\
\hline \multicolumn{3}{|c|}{ Ganhos Efetivos de Junho (20/06 a 30/06) } \\
\hline \multicolumn{1}{|c|}{ Descrição } & Valores & Unidades \\
\hline Carga Média do Moinho: & 210 & $\mathrm{t}$ \\
\hline Tempo de trabalho & 15,56 & $\mathrm{~h} / \mathrm{d}$ \\
\hline & & \\
\hline Baseline (Fator de Consumo & 4,4798 & $\mathrm{KW} /(\mathrm{t} / \mathrm{t}$. resid) \\
\hline & & \\
\hline Dados Reais: & 4,2900 & $\mathrm{KW} /(\mathbf{t} / \mathrm{t}$. resid) \\
\hline & & \\
\hline Delta: & $-0,1898$ & $\mathrm{KW} /(\mathbf{t} / \mathrm{t}$. resid) \\
\hline & & \\
\hline & & $\mathrm{KWh}$ \\
\hline Energia Economizada: & $-39,858$ & $\mathrm{MWh}$ \\
\hline & $-0,039858$ & \\
\hline & & \\
\hline Percentual de Redução: & $-4,24 \%$ & \\
\hline
\end{tabular}

- Sistema de Resfriamento composto por: trocador de calor com um filtro embutido cujo objetivo principal é permitir a troca de calor do óleo com o meio externo e filtragem on line, reduzindo a sua temperatura interna.

- Sistema de Blindagem constituído por: filtro de ar com dessecante, válvula para dreno, filtro de óleo e visor de óleo de coluna que evitará a contaminação do óleo pelo ambiente externo.

\footnotetext{
* Contribuição técnica ao $35^{\circ}$ Seminário de Balanços Energéticos Globais e Utilidades e $29^{\circ}$ Encontro de Produtores e Consumidores de Gases Industriais, 13 a 15 de agosto de 2014, São Paulo, SP, Brasil.
} 


\section{Sistema de Blindagem no Redutor}

Figura 6. Sistema de Resfriamento e de Blindagem.

No dia 18/09/2013 realizado uma nova parada e instalados os sistemas de blindagem e de resfriamento, do qual já no próprio mês de setembro aumentou o percentual de redução para $5,76 \%$ sendo que meta era até $5 \%$.

Tabela 2. Ganhos efetivos óleo sintético em Setembro

\begin{tabular}{|l|c|c|}
\hline \multicolumn{3}{|c|}{ MEDIÇÃO } \\
\hline \multicolumn{3}{|c|}{ Ganhos Efetivos de Setembro (01/09 a 30/09) } \\
\hline \multicolumn{1}{|c|}{ Descrição } & Valores & Unidades \\
\hline Carga Média do Moinho: & 210 & $\mathrm{t}$ \\
\hline Tempo de trabalho & 17,25 & $\mathrm{~h} / \mathrm{d}$ \\
\hline & & \\
\hline Baseline (Fator de Consumo): & 4,4798 & $\mathrm{KW} /(\mathrm{t} / \mathrm{t}$. resid) \\
\hline & & \\
\hline Dados Reais: & 4,2219 & $\mathrm{KW} / \mathrm{t} / \mathrm{t}$. resid) \\
\hline & & \\
\hline Delta: & $-0,2579$ & $\mathrm{KW} / \mathrm{t} / \mathrm{t}$. resid) \\
\hline & & \\
\hline & & \\
\hline Energia Economizada: & $-54,159$ & $\mathrm{KWh}$ \\
\hline & $-0,054159$ & $\mathrm{MWh}$ \\
\hline & & \\
\hline Percentual de Redução: & $-5,76 \%$ & \\
\hline
\end{tabular}

\section{RESULTADOS E DISCUSSÃO}

\subsection{Testes e Medições}

O Consumo Específico $(\mathrm{kW} / \mathrm{t})$ representa a relação entre Demanda $(\mathrm{kW})$ pela soma entre as corpos moedores (carga bola e barra) e o consumo de bauxita e este índice de $01 / 05 / 13$ a 19/06/13 era de 4,4798 do qual foi identificado uma oportunidade de redução.

Após a implementação das ações os objetivos previamente definidos foram alcançados, conforme descrito abaixo:

- Redução em até $5 \%$ no consumo específico $(\mathrm{kW} / \mathrm{t})$ de energia elétrica no moinho de bauxita da Allumina. 


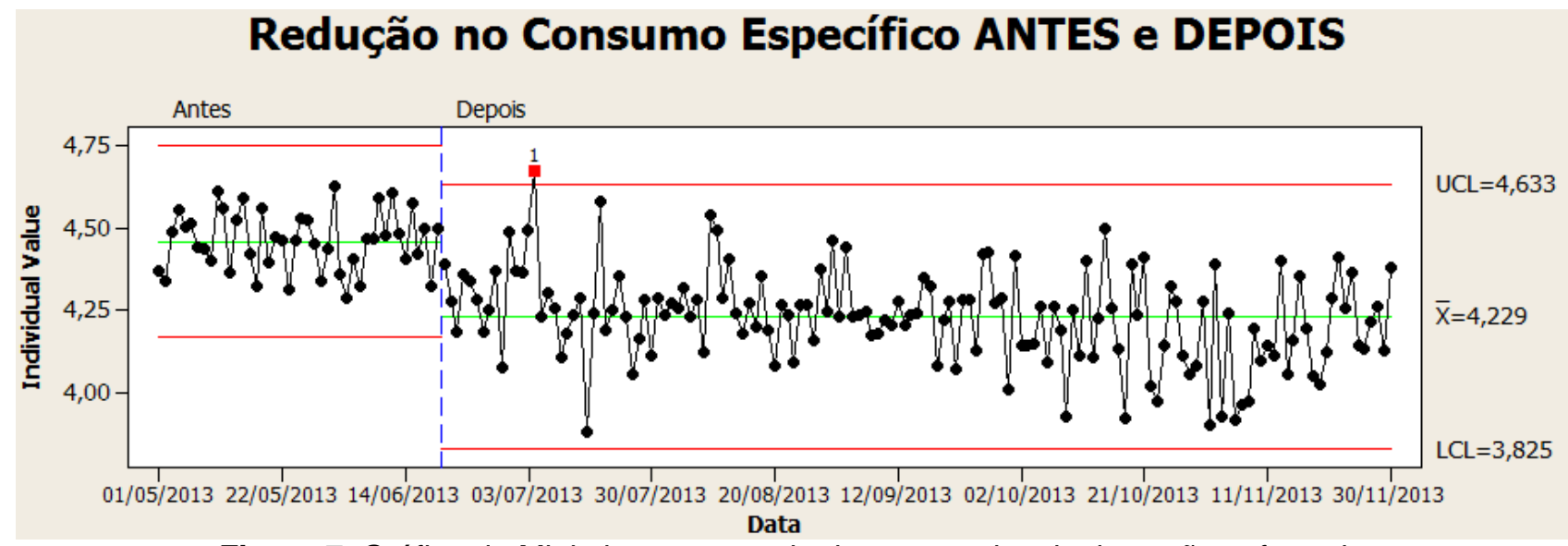

Figura 7. Gráfico do Minitab com o resultado antes e depois das ações efetuadas

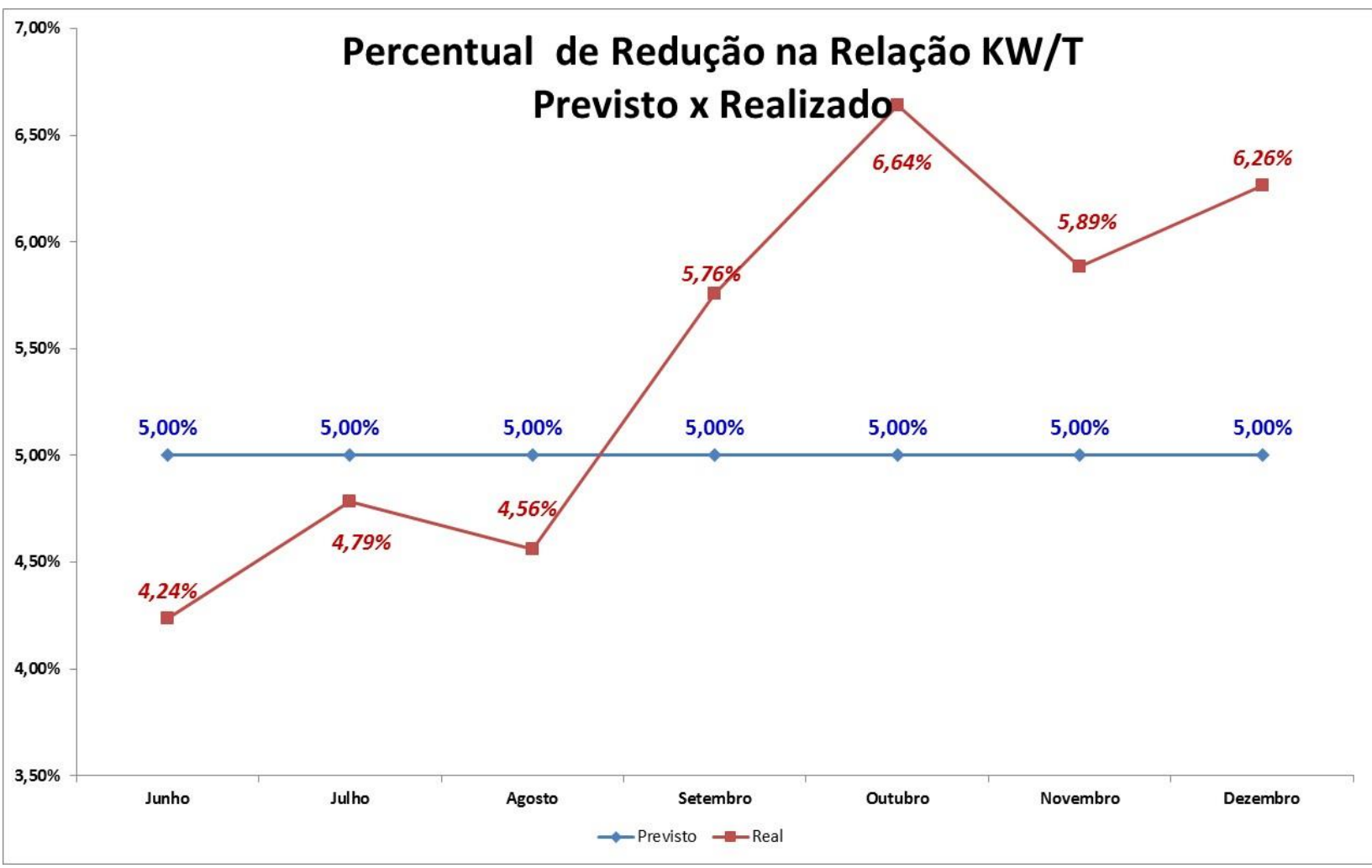

Figura 8. Gráfico percentual do consumo específico

Obs: O valor médio atingido entre Junho e Dezembro de 2013 foi de 5,45\%, onde o maior ganho foi após a implantação do sistema de resfriamento e de blindagem.

- Diminuição da temperatura de trabalho do redutor do moinho em até $20^{\circ} \mathrm{C}$. 

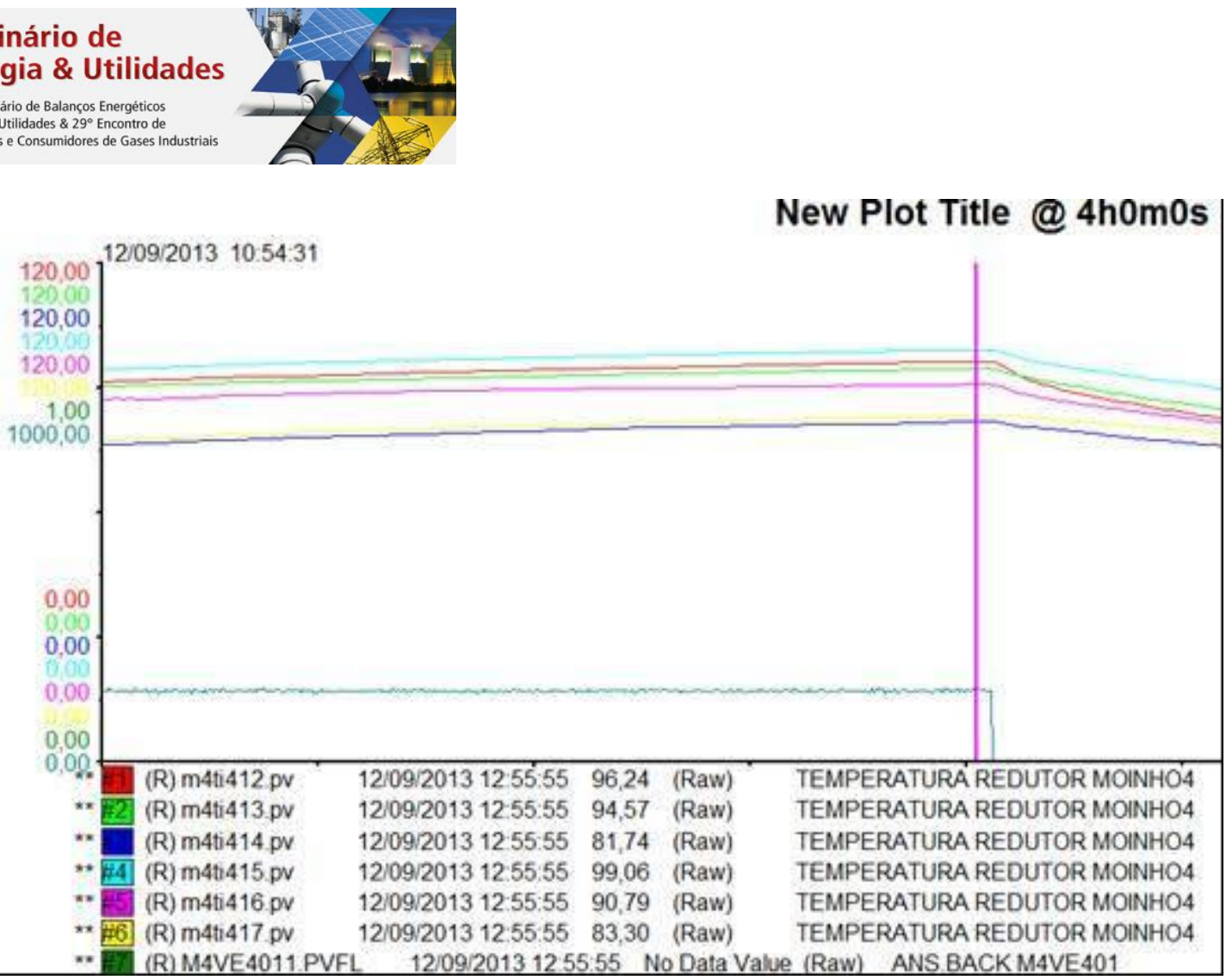

New Plot Title @ 4h0m0s

Figura 9. Gráfico do sistema de temperatura dos mancais do moinho, antes (Média $90,95^{\circ} \mathrm{C}$ ) da implantação do sistema de blindagem e de resfriamento.

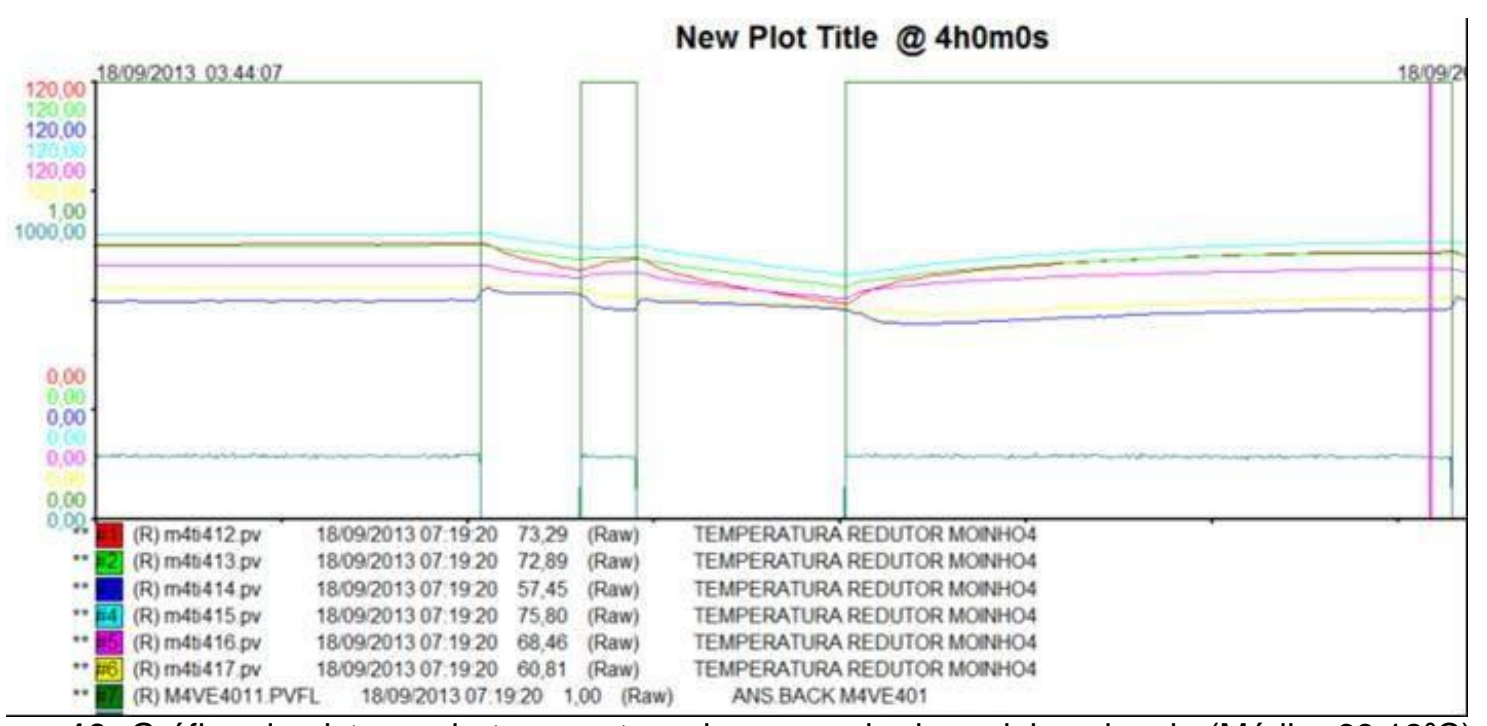

Figura 10. Gráfico do sistema de temperatura dos mancais do moinho, depois (Média: $68,12^{\circ} \mathrm{C}$ ) da implantação do sistema de blindagem e de resfriamento

\section{Obs:}

1) A temperatura média de trabalho do redutor atingido depois do dia 18/09/13 foi de $68,12^{\circ} \mathrm{C}$ o que representa um desvio de $-22,8^{\circ} \mathrm{C}$ e uma redução percentual de aproximadamente $25 \%$, cuja meta era de $20 \%$.

2) No redutor do moinho existem 6 pontos de medição de temperatura que são monitorados constantemente através do sistema de PT100.

\subsection{Análise Financeira}

O investimento inicial do projeto foi de aproximadamente $R \$ 8.000,00$ (Oito mil reais) o que gerou um ganho financeiro de aproximadamente $R \$ 141.300$ ao final de 7 meses

\footnotetext{
* Contribuição técnica ao $35^{\circ}$ Seminário de Balanços Energéticos Globais e Utilidades e $29^{\circ}$ Encontro de Produtores e Consumidores de Gases Industriais, 13 a 15 de agosto de 2014, São Paulo, SP, Brasil.
} 


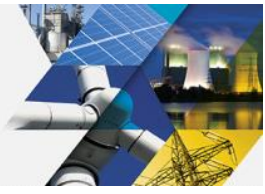

(Jun a Dez/13) contra um orçado de $\mathrm{R} \$ 136.800$ (Centro e trinta e seis mil e oitocentos reais). Conforme tabela 3.

Tabela 3. Ganhos Financeiros e Econônicos

\begin{tabular}{|l|l|}
\hline \multicolumn{2}{|c|}{ Ganhos } \\
\hline Ganho Financeiro & $\mathbf{R} \$ 141.300$ \\
\hline Ganho Econômico & $\mathbf{R} \$ 139.800$ \\
\hline
\end{tabular}

Além do ganho financeiro, deve-se levar em conta os ganhos econômico (Valor de $\mathrm{R} \$$ 139.800) e intangíveis, pois antes da implantação deste projeto ocorria uma parada do moinho a cada 6 dias devido alta temperatura de trabalho do redutor e após a implantação do sistema de blindagem e de resfriamento realizada em 18/09/13 até $31 / 12 / 2013$ não foi constatado, através do sistema de alarme paradas do moinho devido este problema.

Pode ser informado citado como ganhos intangíveis:

- Aumento do fator de confiabilidade, vida útil e de disponibilidade dos equipamentos.

- Redução de exposição ao risco de acidentes da equipe de manutenção/operação.

- Evitar Housekeeping (retrabalhos com processamento de bauxita, soda e limpeza da área).

\subsection{Padronização}

Dando sequência na metodologia do Six Sigma, para garantir a continuidade dos ganhos alcançados, foram padronizadas tarefas tais como:

- Alteração da especificação do óleo mineral no sistema de manutenção interno utilizado na CBA pelo óleo sintético de alta performance para o redutor do moinho, onde somente poderá ser comprado pela área de suprimentos o óleo correto para este equipamento.

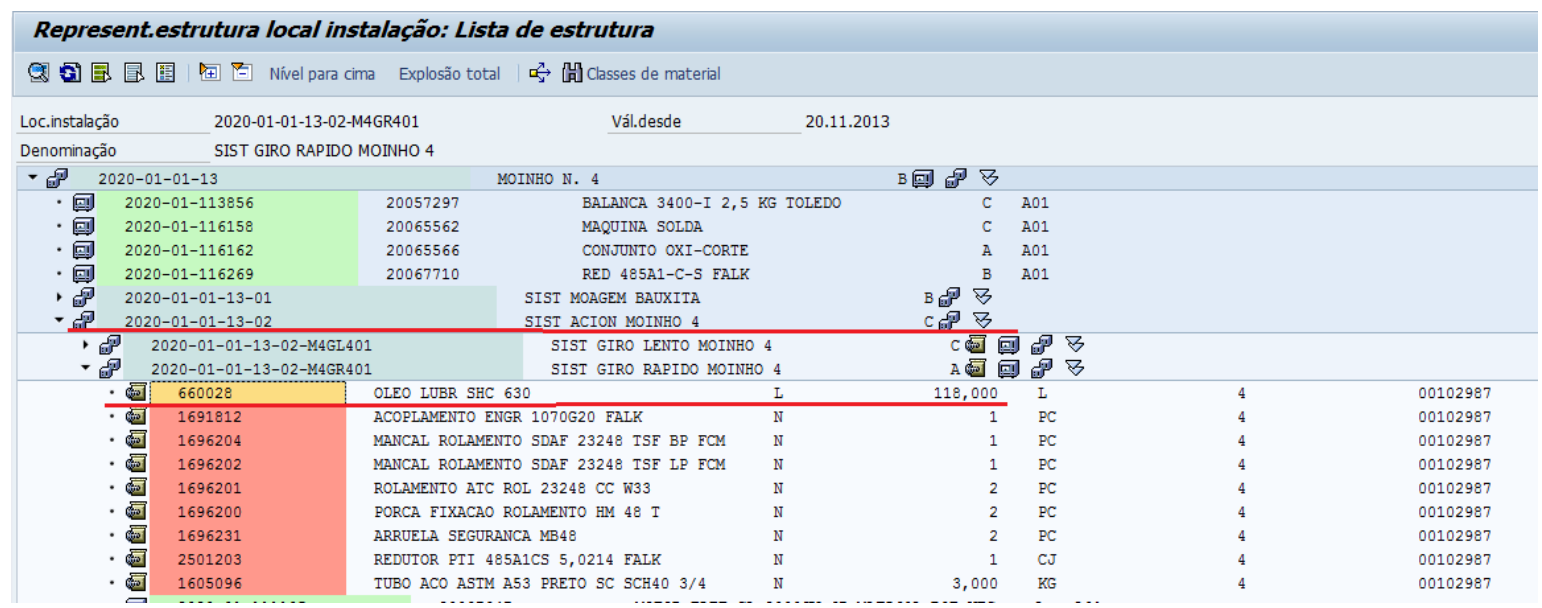

Figura 11. Tela da estrutura local dos equipamentos do redutor do moinho.

- Inclusão do redutor do moinho no Plano de Manutenção atual para a realização da análise do óleo sintético a cada 3 meses 


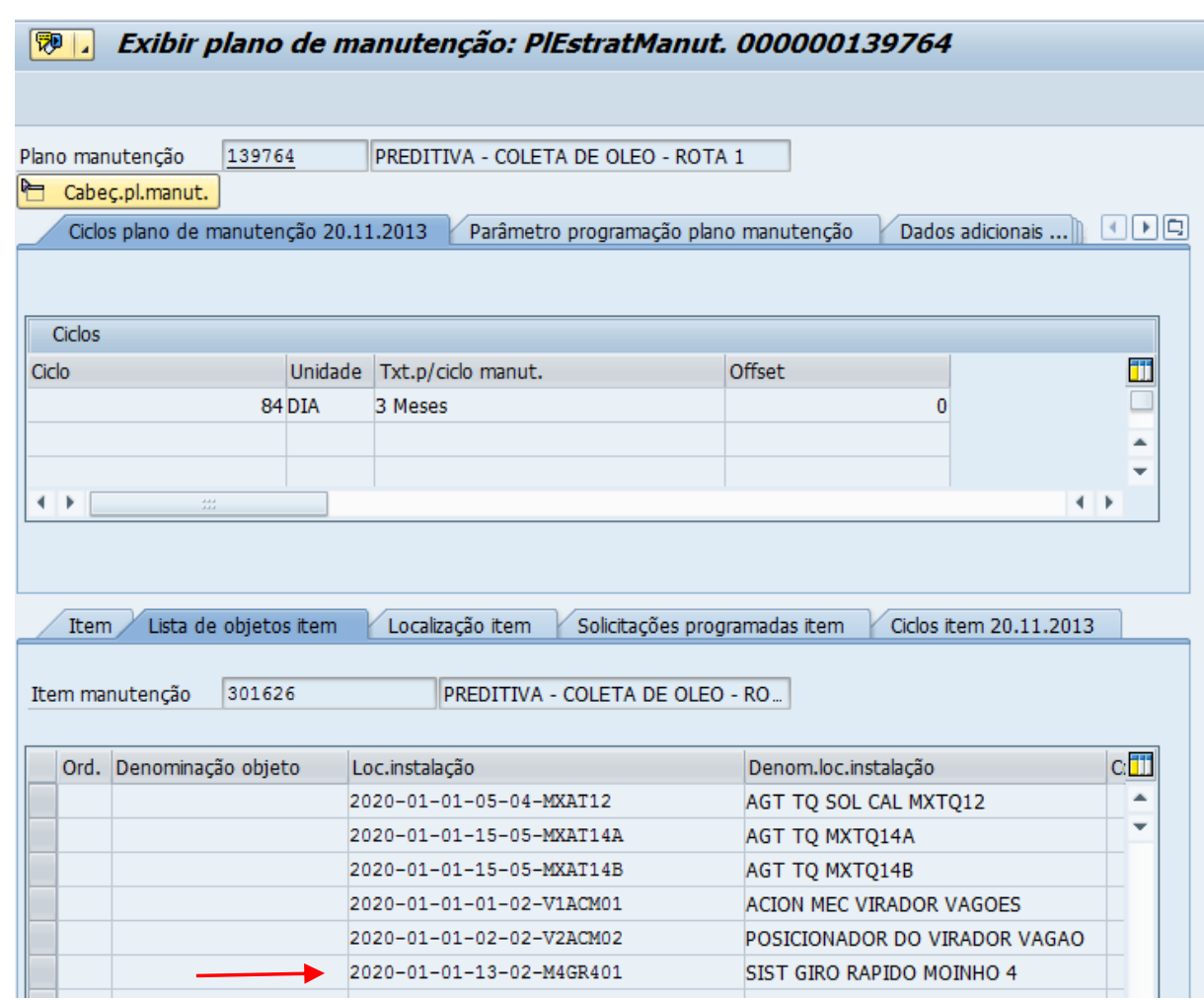

Figura 12. Tela do plano de manutenção de coleta de óleo.

- Inclusão no Plano de Manutenção atual a realização da análise de vibração do redutor do Moinho

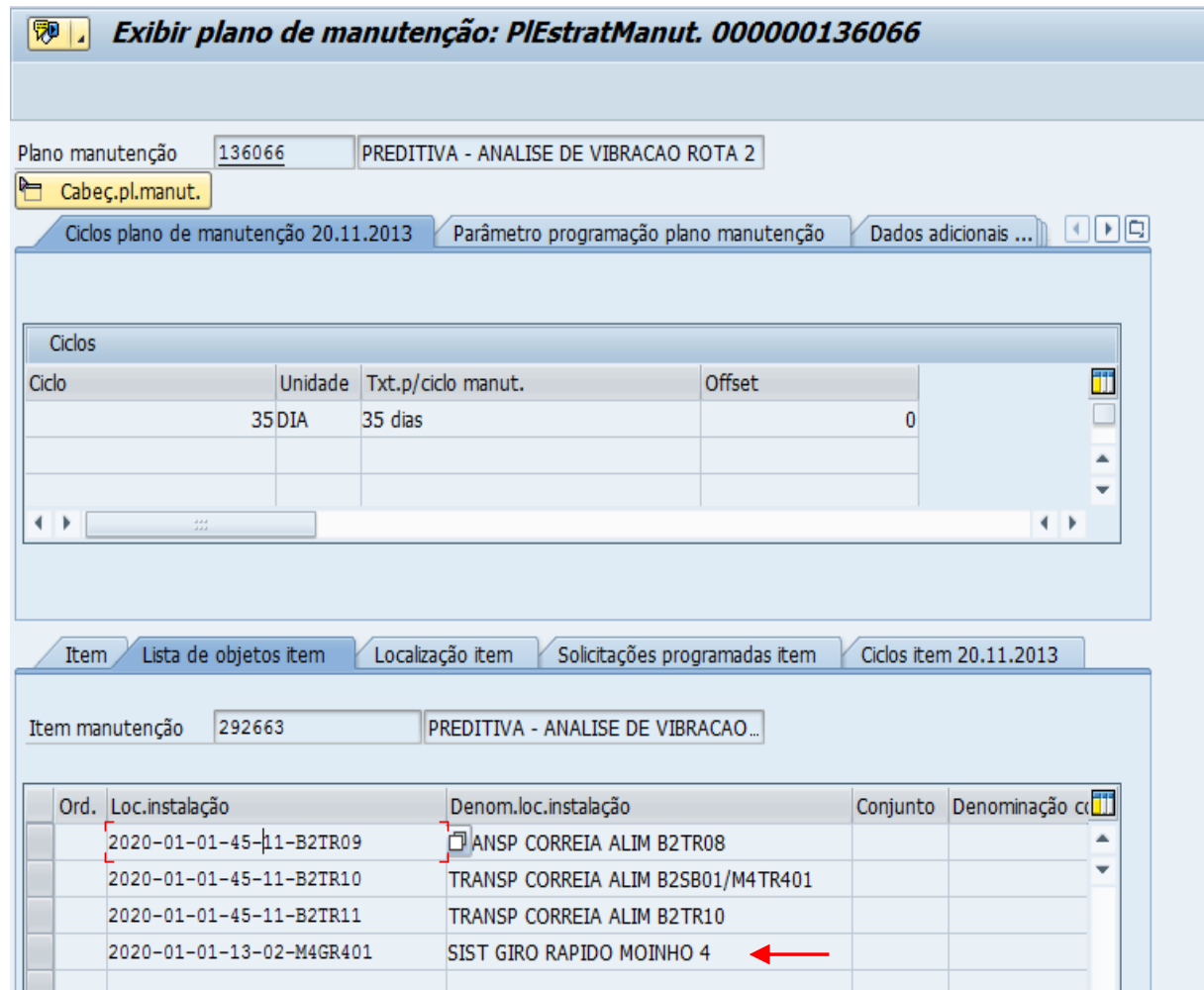

Figura 13. Tela do plano de manutenção de análise de vibração.

- Identificação no corpo do redutor do Moinho 4 que poderá ser utilizado apenas óleo sintético 


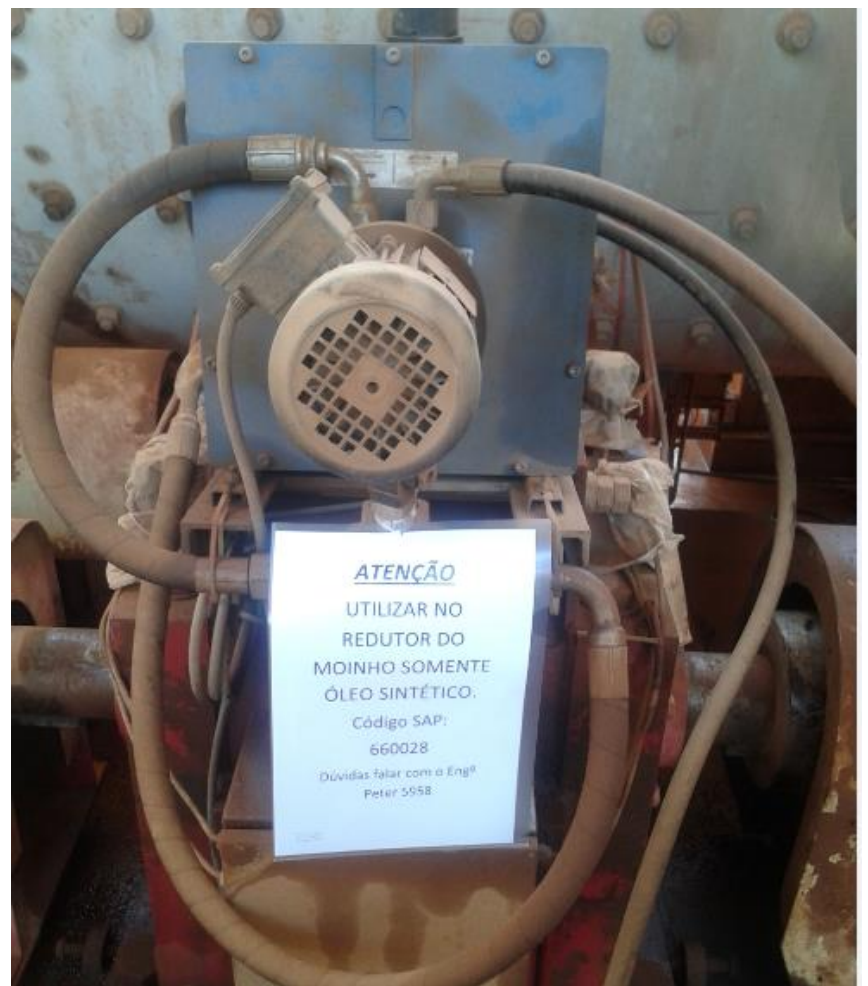

Figura 14. Tela do plano de manutenção de análise de vibração.

- Inserido no Relatório Diário de Processo o Indicador do Consumo Específico (kW/t) mensal, onde os desvios serão automaticamente apontados e de acordo com a metodologia de gestão interna, deverão ser tratados pela equipe de manutenção da fábrica.

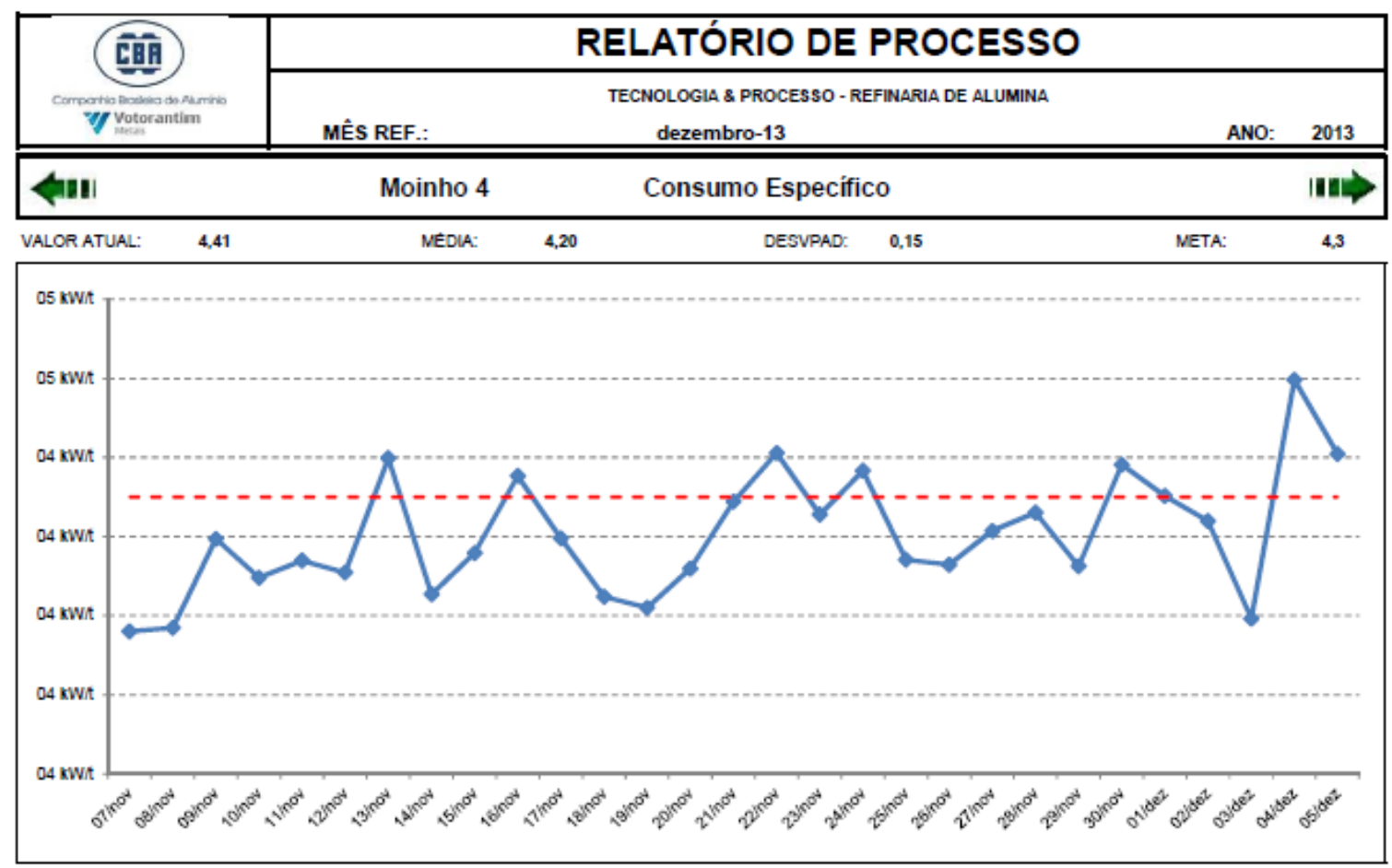

Figura 15. Relatório de Processo do consumo específico do Moinho.

\footnotetext{
* Contribuição técnica ao $35^{\circ}$ Seminário de Balanços Energéticos Globais e Utilidades e $29^{\circ}$ Encontro de Produtores e Consumidores de Gases Industriais, 13 a 15 de agosto de 2014, São Paulo, SP, Brasil.
} 


\section{CONCLUSÃO}

A partir de um problema sistêmico e oportunidade de um ganho energético, foi utilizado um conjunto de ações, conforme descrito ao longo do trabalho que solucionou um problema de manutenção/operação e também trouxe benefício energético através de ações simples com baixo investimento atingindo resultado favorável para a organização.

\section{Agradecimentos}

Agradeço este trabalho ao empenho e dedicação dos colegas de trabalho: Peter Gabriel, Anderson Rodrigo, Bruno Henrique, Lucio da Silva e Donisete Alves que com comprometimento e empenho dedicaram todos os esforços possíveis para o sucesso deste projeto e também o apoio do Gerente de Manutenção Geraldo Torres e do Gerente Geral da Alumina Joaquim Ribeiro.

\section{REFERÊNCIAS}

1 Wikipédia: A enciclopédia livre [página da internet]. Minitab. 2014 [acesso em 17 mai. 2014]. Disponível em: http://pt.wikipedia.org/wiki/Minitab 